\title{
Proposta de utilização do sistema Period Batch Control para redução de lead time em uma empresa de bens de capital
}

\author{
Maico Roris Severino ${ }^{\mathrm{a}, *}$, Muris Lage Junior ${ }^{\mathrm{b}}$, Luciano Campaninic, \\ Alyne de Andrade Guimarães ${ }^{\mathrm{d}}$, Moacir Godinho Filho ${ }^{\mathrm{e}}$, Michelle Aguilera ${ }^{f}$ \\ a,*maico@dep.ufscar.br, UFG, Brasil \\ bmuris@dep.ufscar.br, UFG, Brasil \\ cluciano.campanini@iesa.com.br, UFSCar, Brasil \\ dalyneandrade@gmail.com, UFSCar, Brasil \\ 'moacir@dep.ufscar.br, UFSCar, Brasil \\ fmi_aguilera@hotmail.com, UFSCar, Brasil
}

\begin{abstract}
Resumo
0 objetivo do presente trabalho é apresentar uma proposta para a utilização do sistema PBC (Period Batch Contro), assim como de dois pré-requisitos, a saber: mudança na política de controle da qualidade e criação de uma célula virtual, para reduzir o lead time em uma empresa de bens de capital. 0 método de pesquisa utilizado é o estudo de caso. Resultados previstos de tal implantação indicam que a empresa estudada poderá obter vantagens significativas com a adoção do PBC como, por exemplo, redução de $46,42 \%$ no lead time do produto estudado, diminuição de custos de WIP (Work In Process) em aproximadamente 50\% e redução de 31\% no tempo improdutivo. Esses resultados promissores podem ser alcançados também por empresas com características semelhantes que sigam a proposta apresentada neste artigo. Academicamente, o presente trabalho contribui para aumentar a divulgação do sistema PBC, assunto carente de pesquisas no Brasil.
\end{abstract}

Palavras-chave

Planejamento e controle da produção. Period Batch Control. Redução de lead time.

\section{Introdução}

A sociedade moderna e a tecnologia produziram consumidores impacientes que estão sempre procurando por novos produtos, melhores em qualidade, customizados e produzidos rapidamente. Dessa forma, a manufatura deve responder rapidamente a essas demandas. Nesse sentido, todos os elos da cadeia de suprimentos estão sendo pressionados pela necessidade de redução do lead time. Esse tipo de competição ficou conhecido como competição baseada no tempo, ou Time Based Competition (TBC), a partir dos trabalhos de Stalk (1988) e Schmenner (1988).

Muitos são os benefícios relacionados à redução do lead time (SURI, 1998): redução de custos em todas as etapas do ciclo de vida do produto, maior satisfação dos clientes, aumento da fatia de mercado da empresa e maiores lucros. Diante dessas vantagens evidentes, cada vez mais empresas, especialmente para este trabalho as manufaturas, têm investido esforços para a redução do lead time. No entanto, como salientam Ericksen, Stoflet e Suri (2007), muitas companhias e tomadores de decisão têm uma percepção errada a respeito de ações executadas para reduzir o lead time, pois muitas dessas, na verdade, vão ao encontro da redução desses tempos. Na verdade, muitas das ações com real potencial de reduzir o lead time dos produtos estão intimamente relacionadas às atividades do planejamento e controle da produção (PCP).

0 PCP envolve uma série de decisões com o objetivo de definir o que, quanto e quando produzir e comprar, além dos recursos a serem utilizados 
(CORREAA; GIANESI; CAON, 2007). Algumas das atividades do PCP são: previsão de demanda, planejamento agregado, programação da produção (scheduling), emissão de ordens (atividade realizada pelos chamados ordering systems), dentre outras. 0 presente trabalho foca a atividade de emissão de ordens. Fernandes e Godinho Filho (2007) propõem uma nova nomenclatura para os ordering systems. Sistemas de Coordenação de Ordens (SCO) de produção e compra. De acordo com esses autores, um sistema de coordenação de ordens programa ou organiza/explode as necessidades em termos de componentes e materiais, e/ou controla a emissão/ liberação das ordens de produção e compra, e/ou programa/sequencia as tarefas nas máquinas. Devido a essas características (organização, coordenação, controle, programação e sequenciamento), os SCO têm o potencial de trazer ganhos significativos na redução do lead time.

Fernandes e Godinho Filho (2007) apresentam em seu trabalho uma revisão a respeito de 17 SCO. Dentre esses sistemas, alguns merecem destaque uma vez que vários trabalhos na literatura mostram que tais sistemas trazem melhorias no tocante à redução do lead time. É o caso, por exemplo, do sistema Polca, que de acordo com Suri (1998), Fernandes e Carmo-Silva (2006) é um sistema adequado para a redução do lead time, e do sistema PBC, o qual, de acordo com diversos autores - por exemplo, Zelenovic e Tesic (1988); Burbidge e Halsall (1994), Benders e Riezebous (2002) -, traz ganhos significativos relativos à redução do lead time. Por essa razão, o sistema PBC é o SCO focado no presente trabalho. Esse sistema, muito utilizado na Europa, é pouco conhecido e utilizado em empresas brasileiras.

Dentro desse contexto, o objetivo do presente trabalho é apresentar uma proposta para a utilização do sistema PBC para a redução do lead time em uma grande empresa de bens de capital. Apesar de a proposta principal envolver a implantação do sistema PBC, dois pré-requisitos a essa implantação também são propostos: alteração da política de controle de qualidade da empresa e utilização de célula virtual.

Resultados previstos de tal implantação indicam que a empresa estudada poderá obter vantagens significativas pela adoção do PBC: (i) uma redução de $46,42 \%$ no lead time do produto onde o PBC será implementado; (ii) redução de custos de estoque em processo (WIP) em aproximadamente 50\%; (iii) expectativa de lucros adicionais pela captação de novos projetos, pelo aumento da competitividade da empresa; (iv) maior satisfação dos clientes, com atendimento dos pedidos em praticamente metade do tempo; (v) maior integração dos processos internos para produção do produto; e (vi) redução de 31\% no tempo improdutivo. Esses resultados promissores podem também ser alcançados por empresas com características semelhantes que sigam a proposta apresentada neste artigo. Academicamente, o presente trabalho pretende contribuir com o aumento da divulgação do sistema PBC, assunto carente de pesquisas no Brasil e que tem real potencial de reduzir o lead time dos produtos.

Para alcançar tal objetivo, o presente trabalho foi estruturado da seguinte maneira: na seção 2 é apresentado o referencial teórico que embasa o trabalho, enfatizando-se a redução do lead time e o sistema PBC. Na seção 3 é discutida a metodologia de pesquisa adotada neste trabalho. Nas seções 4 e 5 é descrito o estudo de caso realizado. Primeiramente (seção 4) é feita a coleta e análise dos dados e em seguida (seção 5) é apresentada a proposta de utilização do sistema PBC pela empresa para redução do lead time de produção; ainda nesta seção são descritos os resultados esperados desta proposta. Na seção 6 são feitas as considerações finais do trabalho.

\section{Referencial teórico: redução de lead time e o sistema PBC}

Nesta seção é apresentado um referencial teórico a respeito dos dois principais tópicos tratados neste trabalho: redução de lead time e sistema PBC.

\subsection{Redução de lead time}

Ao longo da história da manufatura muitos foram os paradigmas que se propuseram a auxiliar na árdua tarefa de gerir a manufatura. Primeiramente a Manufatura em Massa, criada por Henry Ford no início do século XX. Em meados da década de 50 começa a surgir no Japão a Manufatura Enxuta (ME), a qual se consolida na década de 70. Mais recentemente, no final dos anos 80 e início da década de 90 foram desenvolvidos outros três importantes paradigmas: a customização em massa (CM), que surgiu em 1987 com Stanley Davis em seu famoso livro "0 futuro perfeito" (DAVIS, 1987); a competição baseada no tempo (TBC) -também denominada de manufatura responsiva (MR) por autores como Fernandes e MacCarthy (1999), proposta por Stalk (1988); e a manufatura ágil (MA), a qual surgiu e foi popularizada em 1991 por um grupo de professores do Instituto Laccoca da Universidade Lehigh, nos Estados Unidos, os quais publicaram neste mesmo ano um relatório (GOLDMAN et al .,1991), prevendo como a competitividade se desenvolveria nos próximos 20 anos. De acordo com Godinho Filho e Fernandes (2005), nenhum desses paradigmas 
deve ser encarado como panaceia para todos os males, uma vez que cada um foca um conjunto de objetivos específicos da manufatura, bem como trabalha de forma eficaz dentro de certas condições da produção e do mercado.

0 presente trabalho foca a redução de lead time; portanto o paradigma da competição baseada no tempo. Nesse trabalho lead time é definido como sinônimo de MCT (Manufacturing Critical-Path). MCT é o tempo típico - em dias corridos - desde que o cliente faz o pedido, passando pelo caminho crítico, até que a primeira peça do pedido seja entregue ao cliente (ERICKSEN; STOFLET; SURI, 2007).

Acredita-se que o paradigma TBC mereça destaque no atual ambiente competitivo pelas seguintes razões:

- Foca a redução do lead time em um ambiente com alta variedade de produtos; essas características representam exatamente 0 atual ambiente competitivo, sendo que outros paradigmas apresentam algumas desvantagens nesse ambiente;

- É um paradigma ainda pouco conhecido e quase não utilizado no Brasil, o que não ocorre, por exemplo, com a Manufatura Enxuta;

- É, dentre os paradigmas citados, aquele que mais utiliza e se beneficia de ferramentas e métodos do $\mathrm{PCP}$, sendo portanto um paradigma adequado a empresas que desejem melhorar o seu PCP.

Como já salientado, o paradigma TBC foi primeiramente proposto por Stalk (1988). Como o próprio nome diz, esse paradigma enfatiza 0 tempo como principal diferencial competitivo, além de uma capacidade de tratar alta variedade de produtos distintos. Blackburn (1991) cita que o TBC deve implantar uma série de métodos destinados a reduzir o tempo de resposta aos clientes. Para Booth (1996), essa nova estratégia de gestão da manufatura enfatiza a redução do tempo de desenvolvimento do produto e do tempo de produção como fatores vitais para o aumento da competitividade de uma empresa. Para Handfield (1995), essa ênfase na redução do tempo não é crítica se pensada como um fim em si mesma; são os benefícios dessa redução que tornam o paradigma atraente.

Apesar de o TBC ter sido proposto no fim dos anos 80 e começo dos 90, a maioria dos trabalhos sobre o tema no início era apenas sobre os benefícios de se reduzir o tempo de resposta e a proposta de algumas ferramentas que seriam benéficas em prol deste objetivo. Foi somente em 1998 que Rajan Suri (SURI, 1998) propôs um método pragmático com a finalidade de se obter reduções nos lead times e, ao mesmo tempo, trabalhando em um ambiente com alta variedade de produtos. Esse método, denominado Quick Response Manufacturing (QRM), foi implantado com sucesso em inúmeras empresas e promoveu o estabelecimento, na Universidade de Wisconsin, em Madison (Estados Unidos), do mais importante centro de pesquisas mundial na área, liderado pelo professor Rajan Suri (Center for Quick Response Manufacturing). Muitas das ferramentas de coleta e análise de dados utilizadas neste trabalho advêm da abordagem QRM.

\section{2. $O$ sistema $P B C$}

O PBC, criado por um consultor inglês chamado R. J. Gigli, é um sistema de coordenação de ordens de fluxo programado, que transforma as necessidades do MPS em necessidade de componentes. Essa transformação é realizada por um departamento de PCP centralizado, caracterizando assim um sistema de produção empurrada (FERNANDES; GODINHO FILHO, 2007).

0 funcionamento básico do PBC é o seguinte:

- Parte-se de um MPS definido para ciclos de igual tamanho - a partir da carteira de pedidos ou previsão de vendas;

- Faz-se a explosão para definir as quantidades a serem produzidas de cada item dentro do ciclo;

- Atribui-se tempo para cada etapa do processo essa atribuição é repetida para todos os ciclos;

Silva e Fernandes (2008) apresentam o funcionamento do sistema $\mathrm{PBC}$ por meio de um exemplo na indústria brasileira de calçados. Esse exemplo encontra-se ilustrado na Figura 1, onde pode-se observar que:

a) Cada ciclo é composto por seis estágios produtivos (acúmulo de pedidos, suprimentos, corte, pesponto, montagem/acabamento e acabamento/ expedição).

b) No período 6, o processo produtivo estará:

- Expedindo o que foi montado no período 5 (completando o ciclo 1);

- Montando o que foi pespontado no período 5 (atividades do ciclo 2);

- Pespontando o que foi cortado no período 5 (atividades do ciclo 2);

- Cortando os materiais que foram separados no período 5 (atividades do ciclo 4);

- Obtendo os materiais de acordo com os pedidos alocados ao período 5 (início do ciclo 5); e

- Acumulando pedidos que serão programados para o próximo ciclo (nesse caso sexto ciclo) ou para ciclos posteriores, caso a demanda atual (pedidos em carteira a alocar) exceda a capacidade de um ciclo. 


\begin{tabular}{|c|c|c|c|c|c|c|c|c|c|c|c|c|c|}
\hline \multicolumn{14}{|c|}{ Períodos } \\
\hline & 1 & 2 & 3 & 4 & 5 & 6 & 7 & 8 & 9 & 10 & 11 & 12 & 13 \\
\hline & Ac & $\mathrm{S}$ & C & $\mathrm{P}$ & $\mathrm{M}$ & $\mathrm{E}$ & \multicolumn{7}{|c|}{ Ciclo - 1} \\
\hline & & Ac & $\mathrm{S}$ & $\mathrm{C}$ & $\mathrm{P}$ & $M$ & $E$ & \multicolumn{6}{|c|}{$\longleftarrow$ Ciclo -2} \\
\hline & & $\longrightarrow$ & Ac & $\mathrm{S}$ & $\mathrm{C}$ & $\mathrm{P}$ & $\mathrm{M}$ & $E$ & \multicolumn{5}{|c|}{$\longleftarrow$ Ciclo -3} \\
\hline & & & & Ac & $S$ & C & $\mathrm{P}$ & $\mathrm{M}$ & $\mathrm{E}$ & \multicolumn{4}{|c|}{$\longleftarrow$ Ciclo - 4} \\
\hline & & & & $\longrightarrow$ & $A c$ & $S$ & C & $\mathrm{P}$ & $\mathrm{M}$ & $\mathrm{E}$ & \multicolumn{3}{|c|}{ Ciclo - 5} \\
\hline & & & & & 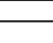 & Ac & $S$ & $\mathrm{C}$ & $\mathrm{P}$ & $\mathrm{M}$ & $\mathrm{E}$ & \multicolumn{2}{|c|}{ Ciclo -6} \\
\hline & \multicolumn{2}{|c|}{ Legenda: } & & & & & & & & & & & \\
\hline & Ac & \multicolumn{9}{|c|}{ Acúmulos de pedidos } & & & \\
\hline & 0 & \multicolumn{9}{|c|}{ Momento da elaboração da programação da produção } & & & \\
\hline & $\mathrm{S}$ & \multicolumn{9}{|c|}{ Suprimentos (obtenção e separação dos materiais) } & & & \\
\hline & C & \multicolumn{9}{|c|}{ Corte } & & & \\
\hline & $P$ & \multicolumn{9}{|c|}{ Pesponto } & & & \\
\hline & $\mathrm{M}$ & \multicolumn{9}{|c|}{ Montagem (acabamento) } & & & \\
\hline & E & \multicolumn{9}{|c|}{ (Acabamento) expedição (envio para os clientes dos produtos acabados) } & & & \\
\hline
\end{tabular}

Figura 1. 0 funcionamento do sistema PBC em um exemplo na indústria calçadista. Fonte: Silva e Fernandes (2008).

Ainda na Figura 1 pode-se notar uma importante característica do sistema PBC: o lead time é exatamente igual ao tamanho do ciclo. $\mathrm{Na}$ Figura 1, pode-se ver que o lead time é igual a seis períodos; é claro que isso supõe que seja possível realizar cada uma das seis operações em exatamente um dia. Para se reduzir o lead time, basta se reduzir o tamanho do ciclo. De acordo com Burbidge (1975), trabalhar com ciclos curtos torna o sistema PBC mais flexível e capaz de seguir rapidamente as alterações na demanda com menor nível de estoque em processo.

Por meio do seu funcionamento, pode-se perceber que a utilização do sistema $\mathrm{PBC}$ requer algumas condições, as quais são citadas por Burbidge (1994):

- 0 tempo de processamento de todos os produtos deve ser menor que um período (portanto, itens com altos tempos de processamento que não conseguem ser reduzidos não podem ser controlados pelo $\mathrm{PBC}$ );

- 0 tempo de set up deve ser reduzido principalmente quando se desejar trabalhar com períodos mais curtos (e com isso reduzir o lead time);

- Os lead times de compra devem ser menores que um período (altos lead times de suprimentos inviabilizam o uso do PBC para controlar estes itens).

Uma maneira de se tentar atenuar a primeira e a segunda limitação é a utilização de arranjo físicocelular (BURBIDGE, 1975). Na verdade, a maioria dos trabalhos que tratam do sistema PBC trabalha com esse sistema em ambientes de manufatura celular - por exemplo: Burbidge (1996), Steele e
Malhotra (1997), Zelenovic e Tesic (1988), Kaku e Krajewski (1995). No presente trabalho a proposta de implantação do sistema $\mathrm{PBC}$ na empresa pesquisada terá como pré-requisito a formação de uma célula virtual, a qual é definida por Suri (1998) como sendo a repartição planejada do tempo disponivel dos recursos compartilhados entre os produtos. Assim, dedica-se parte da capacidade dos recursos para o(s) produto(s) que integra(m) a célula virtual. Na verdade a utilização de uma célula virtual ocorre quando não há possibilidade de transformar o arranjo físico funcional no arranjo físico celular típico (exatamente o caso da empresa estudada).

Mais detalhes a respeito do sistema $\mathrm{PBC}$ são encontrados em diversos trabalhos, como por exemplo: Silva (2002), Zaccarelli (1987) e Burbidge (1975, 1988, 1994).

\section{Metodologia de pesquisa}

A pesquisa realizada neste artigo trabalha basicamente com dois métodos de pesquisa: revisão bibliográfica e estudo de caso.

A revisão bibliográfica é um método bastante utilizado para examinar, de forma abrangente, diferentes abordagens sobre o tema a ser estudado. A revisão da literatura é classificada como um método de pesquisa teórico-conceitual. A pesquisa teórica não implica imediata intervenção na realidade, mas nem por isso deixa de ser importante, pois seu papel é decisivo na criação de condições para a intervenção. De acordo com Berto e Nakano (2000, p. 66), esse procedimento “ [...] é fruto de uma série de reflexões fundamentadas em um fato observado 
ou exposto pela literatura". A pesquisa bibliográfica pode ser aí enquadrada já que o objetivo é explicar um problema a partir de referências teóricas publicadas. No caso dessa pesquisa, é apresentada uma breve revisão da literatura a respeito de redução de lead time (aí se insere o método QRM), PCP e do sistema PBC.

Para Lewis (1998), devido às frequentes mudanças recentes na tecnologia e nos métodos gerenciais, os pesquisadores da área de administração da produção e de operações têm utilizado cada vez mais métodos de pesquisa como o estudo de caso. É uma forma de se fazer pesquisa social empírica, tendo como objetivo a investigação do fenômeno dentro de seu contexto. Para Yin (1990), o estudo de caso envolve o exame de um pequeno número de casos, não tendo por objetivo a generalização. 0 objetivo principal é criar relações e promover o entendimento de um fenômeno estudado. Esse procedimento é do tipo qualitativo e pode ser usado para responder às questões "como" e "por quê" esses fenômenos ocorrem. Para a presente pesquisa, optou-se pela utilização do estudo de caso como um meio de explorar a situação específica de uma empresa que possui um alto lead time para completar a produção de um de seus principais produtos.

A Figura 2 mostra com mais detalhes os passos seguidos nesta pesquisa.

A primeira etapa consistiu na identificação do problema de pesquisa que motivou o trabalho: a constatação do alto lead time para completar a produção de um dos produtos principais da empresa estudada.

Com isso, passou-se para a próxima fase, ou seja, a coleta de dados para elucidação da situação atual da empresa. Os dados utilizados foram extraídos do sistema MRP (Material Requirements Planning) da empresa e de entrevistas pessoais com os operários e com o engenheiro responsável pelo processo.

Para a análise dos dados, terceira fase da pesquisa, utilizou-se o diagrama de valor agregado, que permitiu uma melhor visualização dos tempos e operações envolvidos na fabricação do produto. Para detalhes a respeito dessa ferramenta, ver Suri (1998).

Após isso, com base em entrevistas realizadas na empresa e em uma revisão bibliográfica abrangendo os temas PCP, SCO e competição baseada no tempo/ Quick Response Manufacturing, foi elaborada a proposição da utilização do sistema $\mathrm{PBC}$ para reduzir o lead time de produção do produto estudado. Por fim, foi feito um estudo objetivando-se calcular os resultados esperados com a implantação da proposta.

\section{Estudo de caso: situação atual}

Esta seção está dividida em três subseções. A primeira apresenta a empresa onde foi realizado o estudo de caso. A segunda detalha os setores produtivos para a fabricação dos produtos da empresa. Já na terceira subseção são apresentados o problema de pesquisa, os dados coletados e respectivas análises.

\subsection{A empresa e o produto estudado lobjeto de estudo)}

0 nome da empresa estudada será preservado neste artigo. Tal empresa fornece ao mercado projetos, equipamentos e montagens de grande porte para infraestrutura. Realiza atividades de construções e montagens e oferece soluções para indústrias em geral.

Atualmente conta com duas unidades. A unidade estudada fica em Araraquara, no interior do Estado de São Paulo, estando localizada em um parque industrial com $145.000 \mathrm{~m}^{2}$ de área construída. Essa unidade é uma indústria metal-mecânica fabricante de bens de capital de grande porte e conta com um quadro de aproximadamente 2.100 funcionários, entre diretos e indiretos. Nela são produzidos equipamentos para atender a demanda dos setores de infraestrutura do país, tais como: geração de energia, transporte metro-ferroviário, movimentação e levantamento de materiais, cimento e mineração, portuário, siderurgia, petróleo e petroquímicos, além de realizar serviços de reformas de equipamentos.

Dentre os diversos produtos fabricados nessa unidade, o objeto de estudo desta pesquisa é a esfera de gás, utilizada em indústrias petroquímicas.

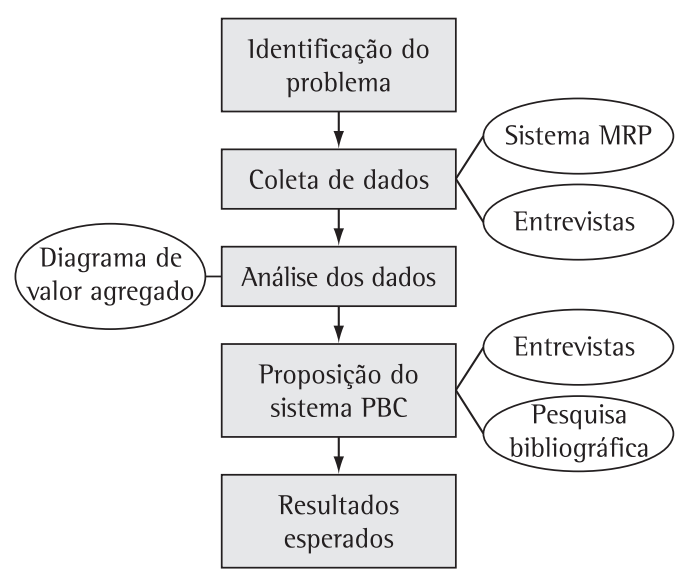

Figura 2. Fluxograma mostrando as fases da pesquisa desenvolvida. 
Grande parte dos gases fabricados nas petroquímicas é armazenada nessas esferas. Esse produto é composto por 54 "gomos" sendo 10 com pernas, 2 com bocais e 48 comuns. Os gomos com pernas e bocais são chamados de gomos especiais. Sua fabricação é muito criteriosa quanto às dimensões das peças. A qualidade dos materiais utilizados é outro requisito fundamental a ser controlado. Após sua produção dentro da unidade, as partes da esfera são transportadas separadamente e se juntam no canteiro de obras no momento da montagem. Atualmente, a esfera pertence ao grupo de produtos que representa $45 \%$ do faturamento da empresa e tende a ser os principais equipamentos a serem fabricados nos próximos anos em função dos altos investimentos no ramo petrolífero.

\subsection{Setores produtivos da empresa estudada}

Nesta seção é apresentada uma descrição dos principais setores produtivos da fábrica, pois, apesar da diversidade dos produtos fabricados, a maior parte dos equipamentos produzidos na unidade de Araraquara utiliza o mesmo processo produtivo, ou seja, a fabricação inicia-se com o corte e dobra, vai para caldeiraria, em seguida usinagem, depois montagem e finaliza com a pintura. A Figura 3 ilustra o fluxo do processo produtivo global.

Como se pode notar, o arranjo físico da fábrica é funcional, com as atividades ou operações diferentes sendo realizadas em setores separados. A seguir é apresentada uma breve descrição dessas atividades.

a) Corte e dobra: nessa atividade a maioria dos materiais cortados são chapas de aço, tubos e barras de diversos comprimentos e espessuras. Todo material cortado tem como referência um desenho elaborado previamente. A dobra é realizada posteriormente ao corte e feita por prensas com capacidades e tamanhos variados

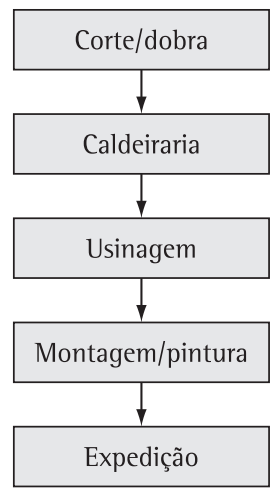

Figura 3. Fluxo do processo produtivo padrão da empresa. para atender as necessidades dos equipamentos a serem fabricados;

b) Caldeiraria: nessa atividade ocorre a montagem das peças cortadas e dobradas até o momento. Após o posicionamento das peças que formarão os equipamentos, elas são soldadas;

c) Usinagem: é uma atividade de precisão realizada por máquinas de pequeno e grande porte; a usinagem serve para efetuar cortes, furos, rasgos e desbastes nas peças que geralmente necessitam de medidas precisas de montagem;

d) Montagem, pintura e expedição: essas atividades estão relacionadas com a montagem de peças que normalmente são fixadas por meio de parafusos e porcas; na pintura, as peças ou equipamentos são tratados superficialmente e recebem camadas de tintas, vernizes ou proteções específicas de acordo com o projeto.

Para o caso específico das esferas, produto focado neste trabalho, as operações nesses setores são mostradas no Quadro 1, a seguir.

\subsection{Coleta e análise de dados: o lead time atual da esfera}

Para o estudo de caso realizado considerou-se apenas a etapa de fabricação. Ou seja, o projeto do produto e a montagem final no cliente foram excluídos da análise. Na fase de coleta de dados foram usadas como técnicas: (i) entrevistas com funcionários da empresa, tendo como instrumento principal um questionário pré-elaborado; e (ii) aquisição de dados de projetos anteriores, a partir do sistema MRP. Os principais dados coletados relativos à esfera foram o lead time do projeto, apontamento das ordens de produção que compõem o caminho crítico e tempos de espera.

Com base nos dados coletados foram elaborados diagramas de valor agregado para a produção da esfera. Esses diagramas, realizados tanto para os gomos comuns como para os especiais, são mostrados nas Figuras 4 e 5 respectivamente. Para condensar a Figura 4, os diagramas dos gomos de 7 a 36 foram omitidos.

Nas Figuras 4 e 5 os espaços em branco são as esperas, e os outros retângulos representam os tempos produtivos nos setores. Nesses diagramas, o lead time total é de 64 semanas, das quais em apenas 8,32 semanas ocorre agregação de valor (somatório dos retângulos hachurados). As outras 55,68 semanas são esperas, não agregando nenhum valor (somatório dos espaços em branco). Ou seja, em média apenas 13\% do tempo total são produtivos, e os outros $87 \%$ são esperas. 
Quadro 1. Descrição das atividades de cada setor para a produção das esferas.

\begin{tabular}{|c|l|}
\hline Setores & \multicolumn{1}{|c|}{ Descrição } \\
\hline Corte & As chapas de aço são cortadas \\
\hline Dobra & $\begin{array}{l}\text { As chapas de aço já cortadas passam pela } \\
\text { calandra e pela dobra para obterem a } \\
\text { curvatura e forma desejada }\end{array}$ \\
\hline Caldeiraria & São feitos os chanfros dos gomos \\
\hline $\begin{array}{c}\text { Controle } \\
\text { de } \\
\text { qualidade }\end{array}$ & $\begin{array}{l}\text { Ocorre entre todas as atividades visando a } \\
\text { inspeção e verificação da conformidade }\end{array}$ \\
\hline $\begin{array}{c}\text { Usinagem } \\
\text { ggomos } \\
\text { especiais) }\end{array}$ & $\begin{array}{l}\text { Os bocais são abertos e também é feita a } \\
\text { soldagem dos suportes e dos bocais nos } \\
\text { gomos diferentes }\end{array}$ \\
\hline Montagem & $\begin{array}{l}\text { É feita a organização do material, proteção e } \\
\text { embalagem para expedição }\end{array}$ \\
\hline
\end{tabular}

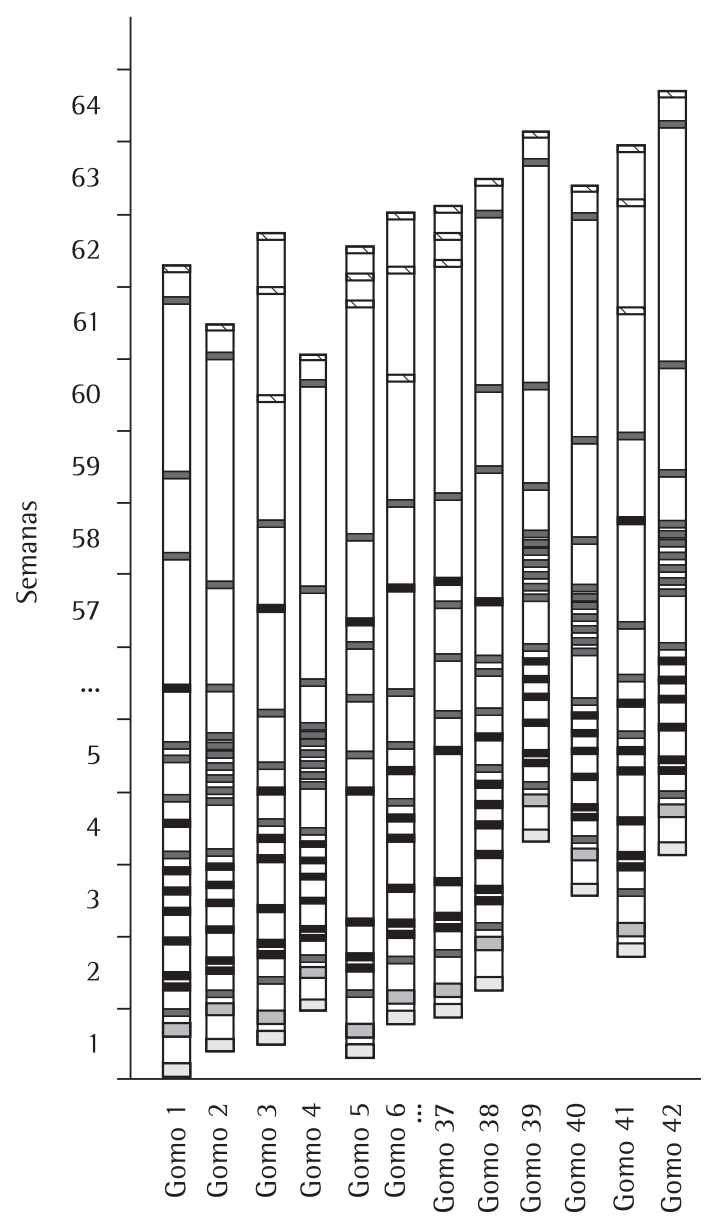

\section{$\square$ Corte $\square$ Dobra $\square$ C.Q. \\ - Caldeiraria $\square$ Montagem}

Figura 4. Diagrama de valor agregado para produção dos gomos de 1 a 42 (gomos comuns).

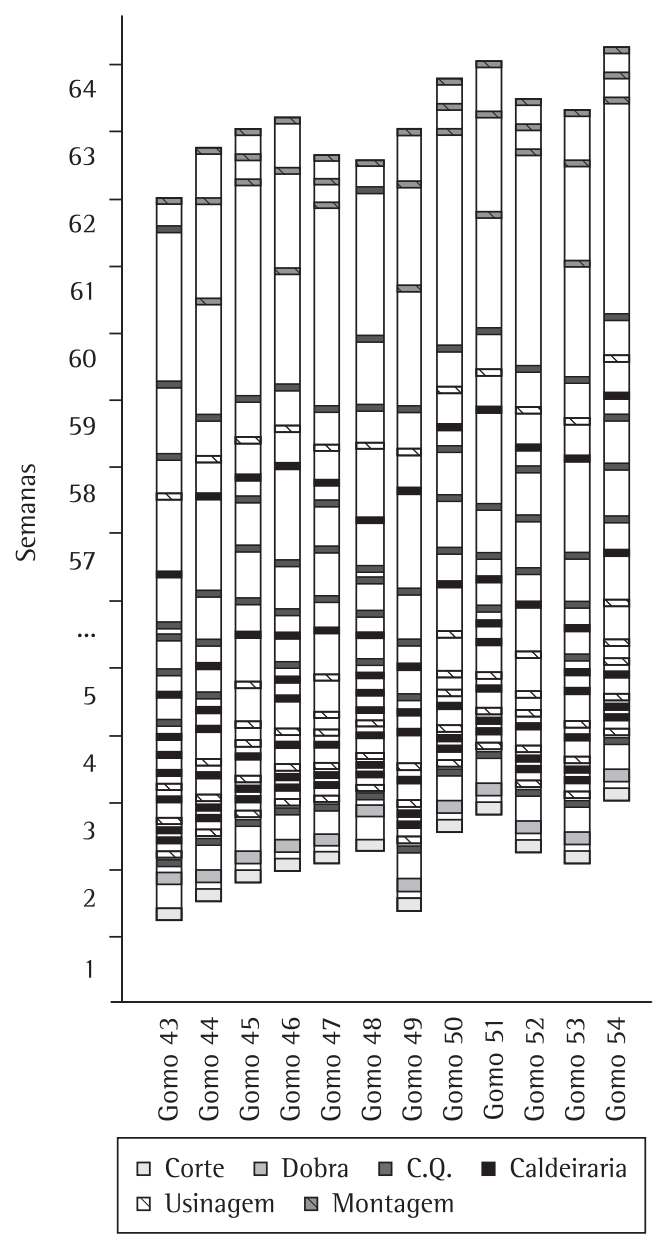

Figura 5. Diagrama de valor agregado para produção dos gomos de 43 a 54 (gomos especiais).

Após um estudo minucioso do problema, concluiu-se que, basicamente, o longo lead time do produto é ocasionado pelos altos tempos de espera dentro dos setores produtivos e entre esses setores. Estes tempos de espera, por sua vez, são resultados de três fatores: a) alta sobrecarga de utilização dos setores produtivos; b) alta variabilidade na chegada das ordens de produção; e c) alta variabilidade no processamento das ordens. Esses três fatores, em maior ou menor grau, são ocasionados pelas políticas de controle de qualidade e planejamento e controle da produção (PCP) utilizadas pela empresa. Essas políticas são as seguintes:

Em relação ao controle de qualidade, a política da empresa estabelece que em todas as peças, ao término das operações, deve ser feita a inspeção de qualidade para só então passar para a operação seguinte. A inspeção de qualidade é realizada por funcionários treinados e certificados pelo cliente, no entanto, são poucos os funcionários com tal formação e muitas vezes eles estão alocados em outras atividades. 
Com relação ao PCP, tem-se que:

- O arranjo físico é basicamente funcional e, devido a isso, todos os produtos (inclusive a esfera) "competem" pelos mesmos recursos produtivos. Esse fator também contribui para o aumento do lead time, uma vez que gera sobrecarga de utilização, aumento da variabilidade na chegada das ordens e aumento da variabilidade no tempo de processamento das ordens (a variedade de produtos em cada centro produtivo é muito grande). Essa relação é bastante citada na literatura - por exemplo, Suri (1998), Hopp e Spearman (2007).

- A lógica de programação atualmente utilizada pela empresa basicamente empurra a produção a partir da chegada das matérias-primas e dos dados gerados pelo sistema MRP da empresa. Reconhecidamente na literatura (por exemplo, TAAL; WORTMANN, 1997; TEMPELMEIER, 1997; SURI, 1998; HO, 2008; dentre outros), o sistema MRP não é um sistema adequado para a redução do lead time, uma vez que ele trabalha com capacidade infinita e por isso apresenta dificuldade em coordenar de fato as ordens de produção no chão de fábrica. Pode-se ver claramente nas Figuras 4 e 5 que inexiste coordenação entre o fim da produção de um gomo e o início da produção de outro em um mesmo processo produtivo ou mesmo entre dois estágios produtivos consecutivos. Isso ocasiona alta variabilidade na chegada das ordens de produção aos centros produtivos, o que origina longas filas e alto lead time. Essa relação entre variabilidade e longas filas e alto lead time é amplamente suportado por uma série de trabalhos oriundos da chamada Teoria de Filas - por exemplo, Karmarkar (1987), Graves, Rinnooy Kan e Zipkin (1993), dentre outros.
- Tamanhos de lotes grandes são utilizados, os quais reconhecidamente aumentam o tempo de espera e, consequentemente, o lead time. Pode-se notar nas Figuras 4 e 5 que todos os gomos são produzidos quase que paralelamente, sendo que o lead time médio de cada gomo é de aproximadamente 55 semanas. De acordo com Vaughan (2006), apesar de a relação tamanho de lote vs. lead time ser amplamente conhecida na literatura específica sobre Teoria de Filas, poucos autores usam essa relação para a prática em gestão de operações. Karmarkar et al. (1985) foram os primeiros a introduzir a relação convexa, em formato "U", existente entre tamanho de lote e lead time. Lambrecht e Vandaele (1996, p. 74) descrevem essa relação:

Tamanhos de lote grandes causarão longos lead times (efeito do tamanho de lote); conforme os tamanhos de lote são reduzidos, o lead time também decrescerá, mas, uma vez que um tamanho de lote mínimo é alcançado, uma redução do tamanho do lote além desse valor causará um aumento na intensidade do tráfego no fluxo produtivo, também resultando em lead times longos (efeito de saturação).

A Figura 6, a seguir, ilustra essas razões discutidas acima para os altos lead times do produto estudado.

Na seção 5, a seguir, é descrita a proposta de melhoria para os problemas encontrados, com destaque para a proposta de implantação do sistema PBC.

\section{Estudo de caso: proposta de utilização do sistema PBC e resultados esperados}

Esta seção está subdividida em duas partes. $\mathrm{Na}$ subseção 5.1 são descritas as propostas para

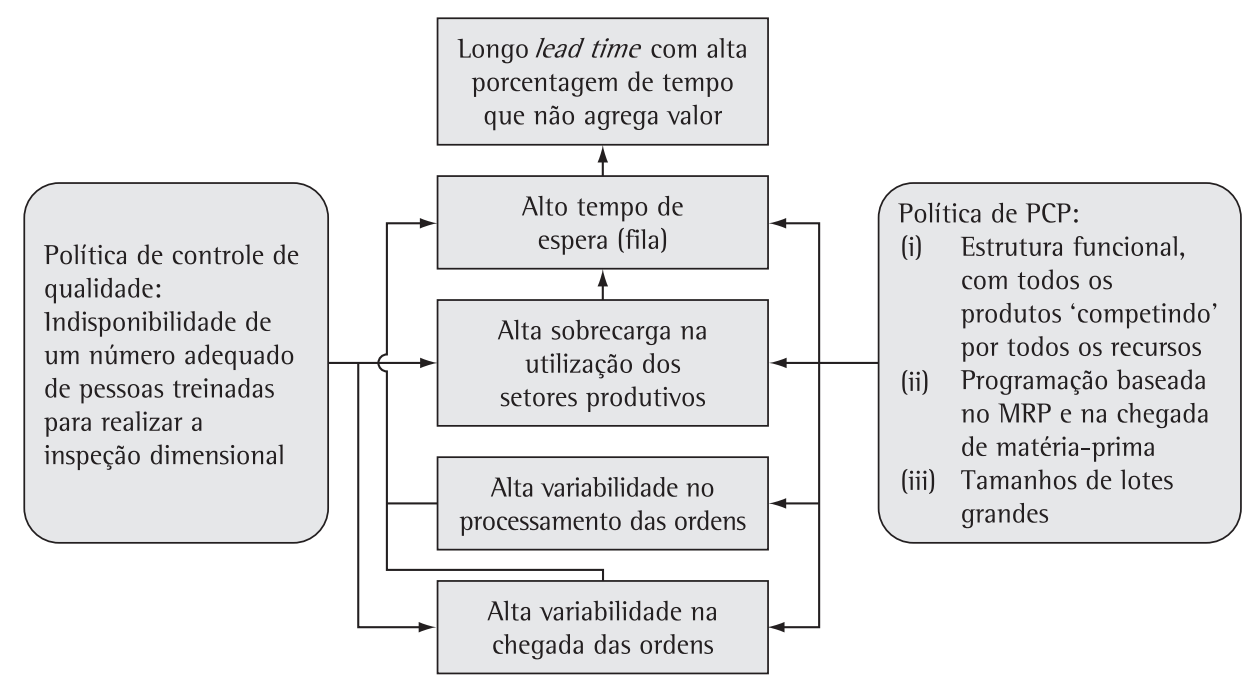

Figura 6. Razões para o longo lead time e tempos de espera do produto estudado. 
solucionar os problemas que ocasionam os longos lead times para produção das esferas. Na seção 5.2 são mostrados os resultados esperados com a implantação das propostas.

\subsection{Proposta de utilização do sistema PBC}

A proposta apresentada neste trabalho visa resolver os problemas relativos às políticas de controle de qualidade e planejamento e controle da produção, mostrados anteriormente. Para isso, além da proposta do sistema $\mathrm{PBC}$ propriamente dito (que contribui para resolver os problemas (ii) e (iii) do PCP), dois pré-requisitos são necessários: mudança na política de controle de qualidade da empresa e implantação de uma célula virtual, os quais contribuirão, respectivamente, para solucionar o problema relativo ao controle de qualidade e o problema (i) do PCP mostrado anteriormente.

A mudança na política de controle de qualidade da empresa se refere a treinar todos os operadores envolvidos na produção da esfera para realização da inspeção e controle da qualidade. Isso visa reduzir as esperas de inspeção de qualidade realizadas após as operações de dobra e caldeiraria. Para cumprir esse objetivo recomenda-se que seja criado um time na empresa responsável pela fabricação de esferas, onde todos os operários participantes façam o treinamento. Assim, ao terminarem cada operação, esses mesmos funcionários podem realizar a inspeção de qualidade, contribuindo para a redução do lead time ao eliminar a espera atualmente existente para a realização do controle da qualidade. Essa medida foi avaliada junto à gerência da empresa, e constatou-se que seria possível sua implantação com um custo relativamente baixo.

A segunda proposta, que na verdade é um pré-requisito à utilização do PBC, é utilizar uma célula "virtual" para as operações dos gomos. lsso é necessário para garantir que essas operações não sofram mais com altas variabilidades entre as chegadas das ordens, pois parte do tempo semanal disponível de cada equipamento estará destinada somente para a fabricação dos gomos, o que garante que os ciclos do $\mathrm{PBC}$ serão obedecidos e que não haverá mais variabilidade nos tempos entre chegada das ordens.
Para a implantação do PBC é necessário destacar as restrições de capacidade e recursos de cada um dos setores envolvidos no processo de fabricação da esfera, pois a partir da implantação da célula virtual (repartição planejada do tempo disponível dos recursos compartilhados entre os produtos) a utilização dos recursos produtivos deve mudar. A seguir são comentadas as restrições de capacidade e a mudança necessária para a utilização da célula virtual.

- Fornecimento: é realizado por caminhões com capacidade de carga de até 30 t;

- Corte: não há restrições de capacidade;

- Dobra: há apenas duas máquinas de dobra, as quais operam em uma taxa de 1,5 gomos por dia, cada uma. Destaca-se, ainda, que essas máquinas são utilizadas por diversos outros produtos da empresa;

- Caldeiraria: há apenas dois dispositivos para a realização do processo, sendo que cada um comporta apenas um gomo e o processo dura cerca de quatro dias. Esses dispositivos são exclusivos para a produção de esferas;

- Usinagem: do mesmo modo que na caldeiraria, há apenas dois dispositivos para a realização do processo, sendo que cada dispositivo comporta apenas um gomo e o processo dura cerca de quatro dias;

- Montagem: não há restrições de capacidade.

Para a implantação da célula virtual, parte do tempo disponível desses recursos fica dedicada à produção dos gomos como mostrado no Quadro 2.

A implantação do $P B C$ deve vir em seguida. 0 sistema $\mathrm{PBC}$ na empresa abrangerá todas as etapas produtivas vistas anteriormente. A seguir é apresentado como o PBC trabalhará em relação a cada uma dessas etapas, procurando-se também estabelecer uma comparação entre o sistema proposto e a atual forma de programação da produção utilizada pela empresa.

0 fornecimento da matéria-prima será coordenado pela produção. Sabe-se que aproximadamente oito toneladas de aço são utilizadas em cada gomo. A programação da produção passará a ser de três gomos por semana na dobra e dois gomos na caldeiraria. Assim, será fornecido aproximadamente um caminhão

Quadro 2. Separação do tempo disponível dos recursos (célula virtual).

\begin{tabular}{|c|c|c|c|c|c|}
\hline & \multicolumn{5}{|c|}{ Recursos } \\
\hline & Corte & $\begin{array}{c}\text { Dobra } \\
\text { Caldeiraria }\end{array}$ & Caldeiraria & Usinagem & Montagem \\
\hline $\begin{array}{l}\text { Tempo utilizado } \\
\text { na célula virtual }\end{array}$ & $\begin{array}{l}1 \text { máquinas de corte durante } \\
3 \text { dias da semana }\end{array}$ & 1 dia da semana & $\begin{array}{l}9 \text { operadores e } \\
\text { os } 2 \text { dispositivos } \\
\text { exclusivos }\end{array}$ & $\begin{array}{l}9 \text { operadores e } \\
\text { os } 2 \text { dispositivos } \\
\text { exclusivos }\end{array}$ & 1 dia da semana \\
\hline
\end{tabular}


por semana, o suficiente para o corte semanal ( 3 gomos $\times 8 \mathrm{t}$ ). Atualmente, o fornecimento de toda a matéria-prima (chapas de aço) é realizado a partir do contrato realizado. Assim, cerca de três caminhões por semana, com uma carga de aproximadamente $25 \mathrm{t}$ cada, abastecem a fábrica. Com isso, em seis semanas, aproximadamente um mês e meio, toda matéria-prima está disponivel para a fabricação. Isso acarreta altos estoques em processo.

0 corte será realizado somente do que for abastecido na semana. Ou seja, lotes de três gomos semanais. Atualmente, é realizado o corte de todos os gomos em um único lote de 54 gomos, ocupando as duas máquinas por aproximadamente um mês e meio, com dedicação exclusiva.

A dobra será realizada em conformidade com o corte do que for abastecido na semana. Ou seja, lotes de três gomos semanais. Atualmente, é realizada a dobra de todos os gomos em um único lote de 54 gomos, durante aproximadamente seis semanas.

$\mathrm{Na}$ caldeiraria, será realizado o processamento em lotes de duas unidades, dessa forma, ocorrendo no máximo duas unidades em fila. Atualmente o processamento já é realizado dessa maneira em função da disponibilidade de apenas dois dispositivos próprios para as operações nos gomos da esfera.

$\mathrm{Na}$ usinagem (operações realizadas somente nos gomos especiais), os gomos serão processados também em lotes de duas unidades. Atualmente, isso já é realizado.

A inspeção de qualidade não será mais requisitada no processo de produção da esfera, visto que nos times de trabalhadores todos serão certificados para a realização da inspeção da qualidade, conforme proposta anterior. Atualmente, é realizada pelo setor específico. No entanto, esse setor está envolvido em todos os projetos da empresa, sendo altamente solicitado entre cada uma das operações.
Por fim, na montagem e expedição serão montados e expedidos dois gomos por caminhão. Será programado o uso de um caminhão por semana e coordenadas as atividades de produção com as de campo. Atualmente não há coordenação dessas atividades com as outras internas, e nem com as atividades em campo.

Portanto, a programação PBC, em função das restrições já destacadas, ficaria do modo exposto acima e resumido no Quadro 3, a seguir, em relação à programação atual:

As Figuras 7 e 8 representam como essas atividades serão programadas com a coordenação de ordens via PBC, sendo os gomos de 1 a 42 gomos comuns, e os de 43 a 54, gomos especiais. Para condensar a Figura 7, os diagramas dos gomos de 7 a 36 foram omitidos.

Nas Figuras 7 e 8, uma observação se faz necessária: os espaços entre o fim das operações de três gomos e o início das operações de outros três gomos se dão em função da utilização da célula virtual, pois apenas uma parte do tempo dos equipamentos de cada semana é dedicada para a produção dos gomos.

\subsection{Resultados esperados}

Portanto, a proposta apresentada no presente trabalho contribui para a resolução dos problemas levantados na seção 4.3, da seguinte maneira:

- Com relação à política de controle de qualidade a solução proposta é a formação de times de produção e treinamento dos integrantes de cada time responsável pela produção das esferas. Isso garante a redução da sobrecarga de utilização nos setores produtivos e redução na variabilidade dos tempos entre chegadas de materiais em processo. Além disso, a implantação do PBC levará a uma melhor coordenação de ordens entre os estágios produtivos, fazendo com que haja a possibilidade

Quadro 3. Resumo da coordenação de ordens via PBC.

\begin{tabular}{|l|l|l|}
\hline \multicolumn{1}{|c|}{ Operação } & \multicolumn{1}{|c|}{ Atual } & $\begin{array}{l}\text { Proposta de utilização do sistema PBC } \\
\text { para a redução do lead time }\end{array}$ \\
\hline Fornecimento de matéria-prima & Toda a matéria-prima de uma vez & Será coordenado pela produção \\
\hline Corte & $\begin{array}{l}\text { Todos os gomos em um único lote de } \\
54 \text { gomos }\end{array}$ & Lotes de 3 gomos semanais. \\
\hline Dobra & $\begin{array}{l}\text { Todos os gomos em um único lote de } \\
54 \text { gomos }\end{array}$ & Lotes de 3 gomos semanais. \\
\hline Caldeiraria & Lotes de 2 unidades & Lotes de 2 unidades \\
\hline Usinagem (gomos especiais) & Lotes de 2 unidades & Lotes de 2 unidades \\
\hline Inspeção da qualidade & Realizada pelo setor específico & Realizada pelos próprios operadores \\
\hline Montagem & $\begin{array}{l}\text { Lotes de 2 gomos, dependendo da da } \\
\text { disponibilidade de caminhão }\end{array}$ & $\begin{array}{l}\text { Lotes de 2 gomos, programados de } \\
\text { acordo com a produção e as atividades } \\
\text { de campo }\end{array}$ \\
\hline
\end{tabular}


de uma melhor programação da utilização dos operadores que estão realizando inspeção de qualidade. Isso resultará na redução de custos de inspeção e melhor utilização dos operadores treinados para a realização desta tarefa;

- Referente ao problema (i) da política de PCP, ou seja, o arranjo físico funcional, é proposta como solução a implantação de uma célula virtual. Isso gera melhor utilização dos equipamentos, redução nas variabilidades dos tempos de processamento e de chegada de ordens;

- Referente ao problema (ii) da política de PCP, ou seja, a utilização de programação empurrada baseada no sistema MRP e na chegada de matérias-primas, pode-se notar que agora existe uma coordenação entre o final da produção de um gomo e o início da produção do gomo seguinte

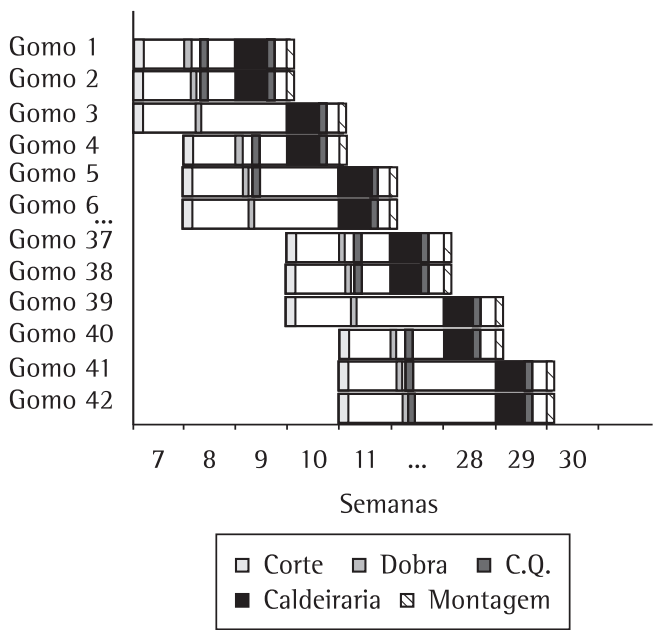

Figura 7. Coordenação de ordens via PBC para os gomos comuns (gomos números 1 a 42).

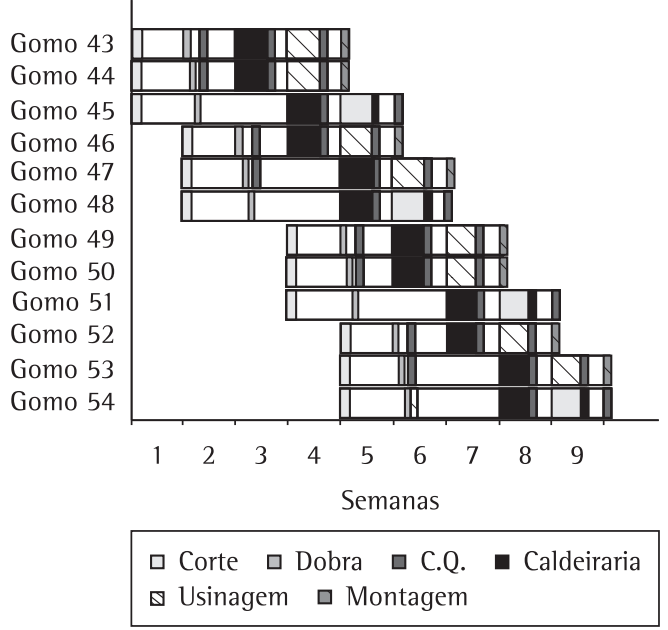

Figura 8. Coordenação de ordens via $\mathrm{PBC}$ para os gomos especiais (gomos de números 43 a 54). (isso pode ser facilmente notado comparando-se as Figuras 4 e 5 com as Figuras 7 e 8). Isso resulta em uma menor variabilidade e por consequência em um menor lead time;

- Referente ao problema (iii) da política de PCP, ou seja, utilização de tamanhos de lotes grandes, os ciclos do PBC representarão uma redução do tamanho de lote (de 54 para três gomos no corte e na dobra), contribuindo bastante para a redução do alto lead time. A comparação entre as Figuras 4 e 5 e 7 e 8 ilustra bem esse fato: na Figura 4, por exemplo, cada gomo comum fica em produção (e portanto permanece como estoque em processo) por cerca de 55 semanas; agora, com o PBC ele permanece em média somente de 3 a 4 semanas.

Realizando-se a análise de tempos produtivos e improdutivos para cada ordem de produção de gomos antes e após a proposta, verifica-se que:

- Gomo comum: antes o lead time médio era de 125 dias, sendo 13\% de tempo produtivo e 87\% de tempo improdutivo. Agora o lead time médio é de 22 dias, sendo 44\% tempo produtivo e 56\% tempo improdutivo;

- Gomo especial: antes o lead time médio era de 125 dias, sendo 13\% de tempo produtivo e 87\% de tempo improdutivo. Agora o lead time médio é de 29 dias, sendo 37\% tempo produtivo e 63\% tempo improdutivo.

A Tabela 1 resume essas informações.

Com essa programação da produção, é possível realizar uma redução de 16 meses (64 semanas) para 8 meses ( 31 semanas). lsso pode ser verificado comparando-se as Figuras 4 e 5 com as Figuras 7 e 8. 0 custo de implantação desse procedimento é nulo, uma vez que se trata apenas da utilização de um método diferente para coordenar as ordens de produção e compra dos gomos no chão de fábrica e do suprimento de aço.

Por outro lado, a redução de lead time esperada resultante da adoção dessa proposta é da ordem de 208 dias, ou seja, roximadamente $46,42 \%$ de redução em relação ao lead time inicial. $\mathrm{Na}$ Figura 7 verifica-se que com a nova programação orientada pelo PBC, em meados do oitavo mês (30 semana), todos os gomos já estão disponíveis para a operação montagem. Sob outro ponto de vista, o primeiro par de gomos (capacidade máxima transportada por caminhão para o cliente) estará disponível a partir da quarta semana (ver Figura 8), ou seja, pode-se programar a entrega de cada par de gomos semanalmente para o cliente, adiantando o faturamento.

Em termos de valores monetários, uma análise simples também mostra grandes benefícios. 0 custo do aço (matéria-prima dos gomos) atualmente 
Tabela 1. Comparação entre os tempos produtivos e improdutivos antes e depois da implantação do PBC.

\begin{tabular}{lcccc}
\hline & $\begin{array}{c}\text { Tempo produtivo } \\
\text { anterior } \\
(\%)\end{array}$ & $\begin{array}{c}\text { Tempo } \\
\text { improdutivo } \\
\text { anterior } \\
(\%)\end{array}$ & $\begin{array}{c}\text { Tempo produtivo } \\
\text { com PBC } \\
(\%)\end{array}$ & $\begin{array}{c}\text { Tempo } \\
\text { improdutivo com } \\
\text { PBC } \\
(\%)\end{array}$ \\
\hline Gomo comum & 13 & 87 & 44 & 56 \\
Gomo especial & 13 & 87 & 37 & 63 \\
\hline
\end{tabular}

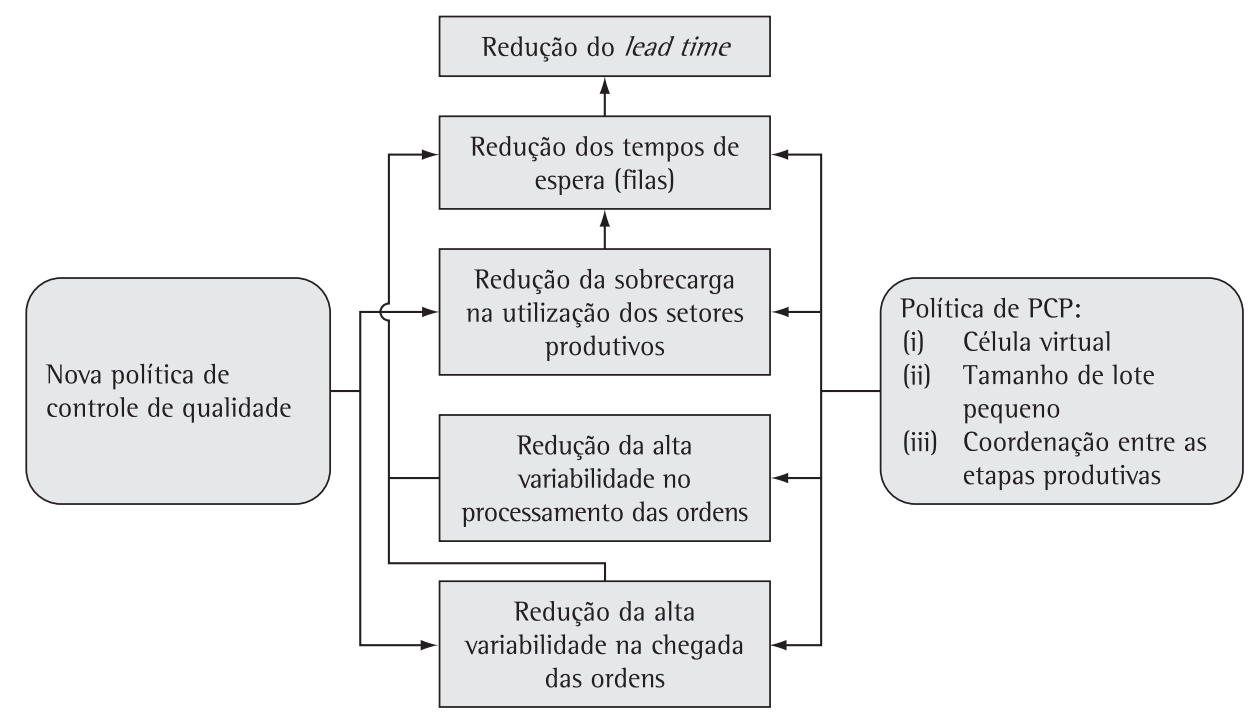

Figura 9. Propostas de melhoria e resultados relacionados.

é de $R \$ 5,00 / \mathrm{Kg}$. Uma esfera pesa por volta de $500.000 \mathrm{Kg}$. Portanto tem-se um custo de material de cerca de $\mathrm{R} \$ 2.500 .000,00$ para uma esfera. Esse material, que antes ficava aproximadamente 16 meses em processo, tinha um custo de estocagem (considerando-se somente o custo de oportunidade de $1 \%$ ao mês) de algo como $\mathrm{R} \$ 25.000,00$ por mês, ou seja, $\mathrm{R} \$ 400.000,00$ no período de 16 meses. Agora, esse custo é em torno de R \$200.000,00, uma vez que o tempo que o material fica em processo caiu de 16 meses para aproximadamente 8 meses.

\section{Conclusão}

Em quase todos os tipos de ambientes industriais existem problemas associados ao lead time. Recentemente todos os elos da cadeia de suprimentos estão sendo pressionados pela necessidade de redução do lead time. No entanto, muitos tomadores de decisão têm uma percepção errada a respeito de ações executadas para reduzir o lead time, empreendendo esforços que muitas vezes são contrários ao objetivo de reduzir o tempo. Dessa forma, adquirem enorme importância propostas que efetivamente garantam a redução do lead time. Esse foi exatamente o objetivo deste trabalho: apresentar uma proposta para a utilização do sistema PBC para a redução do lead time em uma empresa de bens de capital. Apesar de a proposta principal envolver a implantação do sistema PBC, dois pré-requisitos também são propostos: alteração da política de controle de qualidade da empresa e utilização de célula virtual. Academicamente, o presente contribuiu para aumentar a divulgação do sistema PBC, assunto carente de pesquisas no Brasil e que tem real potencial de reduzir o lead time dos produtos.

A pesquisa apresentada neste artigo propôs alterações nas políticas de controle de qualidade e PCP da seguinte forma:

a) Instituiu-se uma nova política de controle de qualidade, na qual todos os trabalhadores participam e isso diminui a sobrecarga de utilização nos setores produtivos e reduz a variabilidade dos tempos entre chegadas de materiais em processo. Além disso, a implantação do PBC levará a uma melhor coordenação de ordens entre os estágios produtivos, o que fará com que haja a possibilidade de melhor programação da utilização dos operadores que estão realizando inspeção de 
qualidade. Isso resultará na redução de custos de inspeção e melhor utilização dos operadores treinados para a realização dessa tarefa.

b) Foi proposta a implantação do sistema PBC para a realização do PCP na empresa. Esse sistema:

b(1) "separa" (célula virtual) recursos para serem utilizados exclusivamente pela esfera, o que contribui para a melhoria da utilização, redução da variabilidade de chegada e variabilidade no processamento das ordens e consequentemente redução do lead time;

$\mathrm{b}(2)$ implanta um sistema que coordena de forma eficaz as ordens no chão de fábrica, reduzindo as variabilidades de chegada e o lead time;

b(3) implanta uma política de lotes pequenos, a qual contribui para a redução dos tempos de espera e consequentemente para a redução do lead time.

A Figura 9 resume essas propostas e resultados relacionados.

Os resultados esperados com a implantação da proposta mostram uma redução de $46,42 \%$ no lead time do produto estudado. Espera-se ainda que tal redução leve aos seguintes benefícios:

- Redução de custos de WIP em cerca de 50\% (o que corresponde a aproximadamente $\mathrm{R} \$ 200.000,00$ );

- Redução do tempo improdutivo (não agregação de valor) em 31\%;

- Expectativa de lucros adicionais pela captação de novos clientes, pois se espera que o produto que antes demorava 16 meses para ser entregue leve agora menos de 8 .

Mais ainda, com a redução do lead time, espera-se melhorar a integração do processo produtivo da empresa, bem como tornar evidentes fontes de ineficiência, problemas de qualidade e desperdícios. Esses resultados promissores podem também ser alcançados por empresas com características semelhantes que sigam a proposta apresentada neste artigo.

\section{Agradecimentos}

Os autores gostariam de agradecer ao CNPq pelo apoio à presente pesquisa.

\section{Referências}

BENDERS, J.; RIEZEBOUS, J. Period Batch control: classic not outdated. Production Planning and Control, v. 13, n. 6, p. 497-506, 2002.

BERTO, R. M. V. S.; NAKANO, D. N. A produção científica nos anais do encontro nacional de engenharia de produção: um levantamento dos métodos e tipos de pesquisa. Produção, v. 9, n. 2, p. 65-75, 2000.
BLACKBURN, J. The time factor. In: BLACKBURN, J. (Ed.). Time-based competition: the next Battleground in Manufacturing. Homewood: Business One lrwin, 1991.

B00TH, R. Agile Manufacturing. Engineering Management Journal, v. 6, n. 2, p. 105-112, 1996.

BURBIDGE, J. L. Planejamento e controle da produção. São Paulo: Atlas, 1988.

BURBIDGE, J. L. Production Flow Analysis. Oxford: Clarendon Press, 1996.

BURBIDGE, J. L. The Introduction of Group Technology. London: Heinemann, 1975.

BURBIDGE, J. L. The use of Period Batch Control (PBC) in the implosive industries. Production Planning and Control, v. 5, n. 1, p. 97-102, 1994.

BURBIDGE, J. L.; HALSALL, J. Group Technology and growth at Shalibane. Production Planning and Control, v. 5, n. 2, p. 213-218, 1994.

CORREAA, H. L.; GIANESI, I. G. N.; CAON, M. Planejamento, programação e controle da produção. 5 ed. São Paulo: Editora Atlas, 2007.

DAVIS, S. M. Future perfect. Massachusetts: Addison Wesley, 1987.

ERICKSEN, P. D.; STOFLET, N. J.; SURI, R. Manufacturing Criticalpath Time (MC7): the QRM metric for lead time. WisconsinMadison: Center for QRM, 2007. (Technical Report)

FERNANDES, F. C. F.; GODINHO FILHO, M. Sistemas de Coordenação de Ordens: revisão, classificação, funcionamento e aplicabilidade. Gestão e Produção, v. 14 , n. 2, p. 337-352, 2007.

FERNANDES, F. C. F.; MACCARTHY, B. L. Production Planning and Control: the gap between theory and practice in the light of modern manufacturing concepts. In: INTERNATIONAL CONFERENCE ON CAD/CAM, ROBOTICS \& FACTORIES OF THE FUTURE, 15, 1999, Águas de Lindóia. Proceedings... Águas de Lindóia: CARs \& FOF, 1999. p. MF2-1-MF2-6. (v. 1)

FERNANDES, N. 0.; CARMO-SILVA, S. Generic POLCA: a production and materials flow control mechanism for quick response manufacturing. International Journal of Production Economics, v. 104, n. 1, p. 74-84, 2006.

GODINHO FILHO, M.; FERNANDES, F. C. F. Paradigmas Estratégicos de Gestão da Manufatura (PEGEMs): elementos chave e modelo conceitual. Gestão e Produção, v. 12, n. 3, p. 333-346, 2005.

GOLDMAN, S. L. et al. Century Manufacturing Enterprise Strategy, An industrial Led View. $21^{\text {st }}$. Bethlehem, PA: lacocca Institute, 1991.

GRAVES, S. C.; RINNOOY KAN, A. H.; ZIPKIN, P. H. Handbooks in Operations Research and Management Science. Amsterdam: Elsevier, 1993. (v. 4)

HANDFIELD, R. B. Reengineering for time-based competition. Homewood: Business One Irwin, 1995.

$\mathrm{HO}$, C. Exploring the compatibility of dampening procedures and lot-sizing rules in MRP systems under uncertain operation environment. International Journal of Production Research, v. 46, n. 18, p. 5097-5120, 2008.

HOPP, W. J.; SPEARMAN, M. L. Factory physics. foundation of manufacturing management. 3 ed. Illinois: Mc Graw Hill, 2007.

KAKU, B. K.; KRAJEWSKI, L. J. Period Batch Control in group technology. International Journal of Production Research, v. 33, n. 1, p. 79-99, 1995. 
KARMARKAR, U. Lot sizes, lead times and in-process inventories. Management Science, v. 33, n. 3, p. 409-418, 1987.

KARMARKAR, U. S. et al. Lot sizing and lead time performance in a manufacturing cell. Interfaces, v. 15, n. 2, p. 1-9, 1985.

LAMBRECHT, M. R.; VANDAELE, N. J. A General Approximation for the Single Product Lot Sizing Model with Queueing Delays. European Journal of Operational Research, v. 95, n. 1, p. 73-88, 1996.

LEWIS, M. W. Iterative Triangulation: a theory development process using existing case studies. Journal of Operations Management. v. 16, n. 4, p. 455-469, 1998.

SCHMENNER, R. The merit of making things fast. Sloan Management Review, v. 30, n. 1, p. 11-17, 1988.

SILVA, F. M. Um sistema de Planejamento e Controle da Produção para indústrias de calçados infantis pertencentes a um industrial cluster. Dissertação (Mestrado em Engenharia de Produção) - Universidade Federal de São Carlos, São Carlos, 2002.

SILVA, F. M.; FERNANDES, F. C. F. Proposta de um sistema de controle da produção para fabricantes de calçados que operam sob encomenda. Gestão e Produção, v. 15, n. 3, p. 523-538, 2008.

STALK, G. Time: the next source of competitive advantage. Harvard Business Review, v. 66, n. 4, p. 41-51, 1988.
STEELE, D. C.; MALHOTRA, M. K. Factors affecting performance of period batch control systems in cellular manufacturing. International Journal of Production Research, v. 35, n. 2, p. 421-446, 1997.

SURI, R. Quick Response Manufacturing: a companywide approach to reducing lead times. Portland: Productivity Press, 1998.

TAAL, M.; WORTMANN, J. C. Integrating MRP and finite capacity planning. Production Planning and Control, v. 8, n. 3, p. 245-254, 1997.

TEMPELMEIER, H. Resource-constrained materials requirements planning - MRP rc. Production Planning and Control, v. 8, n. 5, p. 451-461, 1997.

VAUGHAN, T. S. Lot size effects on process lead time, lead time demand, and safety stock. International Journal of Production Economics, v. 100, n. 1, p. 1-9, 2006.

YIN, R. K. Case study research: design and methods. Newbury Park: Sage Publications, 1990.

ZACCARELLI, S. B. Programação e controle da produção. 8 ed. São Paulo: Pioneira, 1987.

ZELENOVIC, D. M.; TESIC, Z. M. Period Batch Control and group technology. International Journal of Production Research, v. 26, n. 3, p. 539-552, 1988.

\title{
Lead time reduction in a capital goods company by means of the implementation of Period Batch Control system: a proposal
}

\begin{abstract}
The goal of this work is to present a proposal for the use of the PBC (Period Batch Control), as well as two prerequisites, namely, to change the policy of quality control and creation of a virtual cell, to reduce the lead time in a company which produces capital goods. Case study research is the methodology used in this paper. Expected results of this implementation indicate that the company can obtain significant benefits by the adoption of PBC, such as $46.42 \%$ lead time reduction, reduction on WIP (Work In Process) costs in approximately 51.56\% and unproductive time in $31 \%$. These promising results can be achieved by companies with similar characteristics. Academically, this work contribute to increase the dissemination of the PBC, a subject in need of research in Brazil.
\end{abstract}

\section{Keywords}

Production planning and control. Period batch control. Lead time reduction. 